\title{
SISTEM INFORMASI NILAI TAMADUN DI SDIT MAFATIH BEKASI MENGGUNAKAN JAVA DAN MYSQL
}

\author{
Muhammad Ginanjar Sabarudin', Een Juhriah², Maimunah ${ }^{3}$ \\ Program Studi Informatika, Fakultas Teknik dan Ilmu Komputer, Universitas Indraprasta PGRI \\ Jalan Raya Tengah No 80, Kelurahan Gedong, Pasar Rebo, Jakarta Timur \\ muhginanjar@gmail.com ${ }^{1}$, eenunindra@yahoo.co.id ${ }^{2}$, maimunah@informatikaunindra.org ${ }^{3}$
}

\begin{abstract}
Abstrak
SDIT Mafatih memiliki kurikulum tersendiri yang menjadi ciri khas dari sekolah tersebut yaitu tamadun. Dengan adanya ciri khas tertentu, diperlukan laporan tersendiri yang terpisah dari pelajaran pada umumnya. Saat ini laporan tamadun, tidak tertata rapi, tidak dapat dicari kembali setelah tahun ajaran baru, dan banyak lagi masalah lainnya. Maka, tujuan dari penelitian ini adalah untuk memudahkan administrator dalam mengelola data nilai tamadun siswa sehingga dapat menjadi solusi terhadap permasalahan berkaitan dengan nilai tamadun secara lebih cepat, tepat dan efisien. Metode penelitian yang digunakan dalam sistem informasi nilai tamadun ini adalah metode waterfall, sehingga sistem informasi nilai tamadun yang sebelumnya belum ada, bisa di implementasikan dan menjadi berguna dalam membuat laporan nilai tamadun per siswa setiap tahun ajarannya. Pada Penelitian ini telah dirancang sebuah sistem informasi nilai tamadun yang dibuat menggunakan alat bantu perancangan sistem yaitu Diagram Aliran Data (DAD) konteks, nol dan rinci dengan menggunakan bahasa pemrograman JAVA dengan Netbeans IDE, dan database MYSQL menggunakan XAMPP. Penelitian ini menghasilkan Sistem Informasi yang bisa menghasilkan laporan nilai tamadun secara terintegrasi, sistematis, dan efisien. Laporan yang dibuat dalam sistem Informasi ini, sudah disesuaikan dengan kebutuhan pengguna, diantaranya dapat dipilih sesuai kelas, tahun ajar dan siswa.
\end{abstract}

Kata Kunci : Sistem Informasi, Nilai Tamadun Sdit Mafatih Bekasi, Java dan MySql

\begin{abstract}
SDIT Mafatih has a special curriculum that is characteristic of the school is tamadun. With certain distinctive features, separate reports are required apart from the general lessons. The current report is tamadun, not ordered neatly, cannot be searched after the new school year, and many other problems. Thus, the purpose of this research is to facilitate the administrator to manage the value data of student values so that it can be a solution to problems related to the value of tamadun more quickly, precisely and efficiently. The method of research used in the information system of this value is waterfall method, so that the information system that previously did not exist, can be implemented and become useful in making a report of the value of tamadun student each year of its teachings. In this research has designed an information system of tamadun values made using a system design tool namely Data flow Diagram (DAD) context, Nol and detailed using the JAVA programming language with NETBEANS IDE, AND the MYSQL DATABASE using $X A M P P$. This research resulted in an information system that could produce a report of tamadun value in an integrated, systematic, and efficient manner. The reports made in this information system have been adapted to the needs of the user, among them can be chosen according to classes, years of teaching and students.
\end{abstract}

Keyword : Information System, Tamadun Values, Sdit Mafatih Bekasi, Java dan MySql

\section{PENDAHULUAN}

Sekolah Dasar Islam Terpadu (SDIT) Mafatih sebagai salah satu sekolah yang berlokasi di Bekasi, merupakan salah satu sekolah favorit yang sedang berkembang dan berupaya untuk terus meningkatkan pelayanan kepada para stakeholder (orang tua siswa, pihak yayasan dan Dinas Pendidikan). Dengan kurikulum yang tidak hanya mengambil kurikulum dari Dinas Pendidikan, tetapi juga ditambah dengan kurikulum yang menjadi nilai tambah yang bisa dilihat oleh masyarakat kepada SDIT Mafatih ini. Kurikulum yang diterapkan oleh SDIT Mafatih, menjadi ciri khas, atau pengajaran yang ditonjolkan untuk menarik para orang tua, sehingga menyekolahkan anak-anak mereka di sekolah tersebut. Untuk SDIT Mafatih, karena memiliki visi dan misi sekolah yang unik yaitu mampu menerapkan pengetahuan tentang Al-Quran dan Al-Hadits dalam kehidupan, membangun adab dan kepemimpinan siswa, maka sekolah ini pun menyelenggarakan pengajaran Tamadun (Akhlak dan 
Adab). SDIT Mafatih saat ini sudah memiliki sistem penilaian untuk pelajaran-pelajaran yang umumnya dipelajari di sekolah lain. Seperti untuk pelajaran Matematika, IPA, IPS, Bahasa Inggris, Bahasa Indonesia, atau pelajaran-pelajaran umum lainnya. Sistem penilaian ini memiliki hasil cetak raport yang sama dengan sekolah lain pada umumnya. Untuk pengajaran Tamadun, Sekolah ini membuat cetak raport khusus. Cetak raport nilai Tamadun ini dibuat dengan cara manual, menggunakan Excel dan Word, tetapi dengan beberapa kendala sehingga data-data yang didapatkan tidak akurat, tidak cepat didapatkan, juga akan hilang sewaktu-waktu, disaat akan melakukan laporan ke Dinas terkait, data-data yang akan diambil susah untuk didapatkan.

Berdasarkan latar belakang yang telah diuraikan di atas, maka peneliti merumuskan beberapa masalah sebagai yaitu bagaimana merancang sebuah aplikasi nilai Tamadun pada SDIT Mafatih di Bekasi secara terkomputerisasi sehingga lebih cepat, akurat dan efisien, bagaimana mengatasi pencatatan nilai Tamadun sehingga informasi nilai Tamadun setiap siswa bisa didapatkan dengan mudah dan tercatat secara sistematis dan terintegrasi, bagaimana cara agar proses laporan nilai Tamadun bisa disesuaikan berdasarkan tahun ajaran, semester, dan siswa, atau kelas. Tujuan penelitian yang peneliti lakukan adalah merancang aplikasi nilai Tamadun agar dapat memberikan data yang cepat, akurat dan efisien, merancang pencatatan nilai Tamadun yang bisa diakses kapanpun karena tersimpan di database sehingga mempermudah user dalam menggunakannya, memperbaiki proses pencatatan atau pelaporan data nilai Tamadun, memecahkan masalah dengan format laporan yang berubah, tetapi bisa disesuaikan dengan data yang dibutuhkan, memperlancar operasi pegawai administrasi untuk mengolah data nilai tamadun. Penelitian ini diharapkan mampu memberikan kegunaan praktis maupun akademis, yaitu menjadi salah satu bahan masukan atau bahan acuan dan menjadi referensi bagi penelitian yang sama dengan yang dibahas pada penelitian untuk mencapai hasil yang diinginkan dan memuaskan.

\section{PENELITIAN RELEVAN}

Perancangan Sistem Pengolahan Data Nilai Siswa Berbasis Java di SMP At-Taqwa Kec. Sawah Besar Jakarta, yang diteliti oleh (Andrian, 2019) memiliki tujuan yaitu untuk mempermudah dalam mengelola data nilai siswa SMP At-Taqwa, agar proses penyajian data menjadi efektif dan efisien, selain itu perancangan ini dapat membantu menyelesaikan permasalahan pekerjaan yang berkenaan dengan pengolahan data nilai siswa dapat terselesaikan dengan cepat, tepat, akurat guna mengefesiensikan waktu pekerjaan. Penelitian ini sangat relevan dengan penelitian yang sedang peneliti tulis saat ini, menggunakan bahasa pemrograman yang sama yaitu Java, juga target penelitian yang sama, yaitu sekolah. Perbedaan pada penelitian ini dengan penelitian yang sedang ditulis saat ini, adalah Nilai yang menjadi objek penelitiannya berbeda. Dalam penelitian ini, peneliti menggunakan nilai Tamadun yang memiliki sub pelajaran, sehingga berbeda dengan nilai pelajaran yang lain. Perancangan Sistem Informasi Sirkulasi Buku pada Perpustakaan SMP Negeri 103 Jakarta, yang diteliti oleh (Pratama et al., 2019) memiliki tujuan yaitu membuat perancangan sistem informasi sirkulasi buku pada Perpustakaan SMP Negeri 103 Jakarta ditinjau dari pendataan peminjaman buku dan pengembalian buku, serta pembuatan laporan data peminjaman buku perpustakaan. Sehingga hasil dari penelitian ini adalah model dan aplikasi dari sistem informasi sirkulasi buku perpustakaan untuk dimanfaatkan oleh Perpustakaan SMP Negeri 103 Jakarta. Penelitian ini berkaitan dengan penelitian yang sedang ditulis saat ini, yaitu dengan target penelitian sekolah. Perbedaannya adalah dalam objek penelitian. Objek penelitian penelitiannya adalah sirkulasi buku, sedangkan untuk penelitian yang saat ini sedang peneliti lakukan adalah mata pelajaran Tamadun.

\section{METODE PENELITIAN}

Penelitian ini, peneliti menggunakan Metode Waterfall. Model waterfall disebut juga sebagai model siklus hidup klasik. Model ini memungkinkan pemecahan misi pengembangan yang rumit menjadi beberapa langkah logis (desain, kode, pengujian, dan seterusnya) dengan beberapa langkah yang pada akhirnya menjadi produk akhir yang siap pakai (Purwanto \& Raharja, 2019). Metode pengumpulkan data peneliti lakukan untuk mendapatkan data dan informasi yang mendukung hasil dari penelitian ini antara lain : 
1. Observasi

Peneliti mengamati dan mempelajari sistem pengolahan nilai tamadun baik manual maupun menggunakan data Microsoft Office Excel yang terdapat di SDIT Mafatih dari mulai pendataan siswa, penginputan nilai siswa dari file ke Microsoft Office Excel, pencetakan raport nilai tamadun serta pembuatan laporan nilai tamadun.

2. Wawancara

Wawancara merupakan proses memperoleh keterangan untuk tujuan penelitian dengan cara melakukan tanya jawab kepada responden ataupun pihak-pihak yang terkait, dengan mengajukan beberapa pertanyaan yang ada kaitannya dengan kebutuhan data yang dikumpulkan oleh peneliti.

Peneliti mewawancari Saudari Ratna D. Kurniasih, selaku Guru/Karyawan yang bertanggung jawab dalam mendata Nilai Tamadun Kelas Enam. Beliau menyatakan bahwa penilaian Mata Pelajaran Tamadun, terkendala dalam hal pengisian nilai Tamadun yang berpotensi mengalami kesulitan, pengarsipan Nilai Tamadun per siswa dan perkelas yang akan berkesulitan pula ketika akan membuat laporan nilai Tamadun rata-rata perkelas atau per siswa. Ketika berganti tahun ajar, dan guru yang mengajar kelas berganti pula, akan berkesulitan untuk membuat laporan nilai Tamadun siswa pada tahun ajar sebelumnya.

3. Dokumentasi

Peneliti melakukan pengumpulan data dengan cara melihat dan mencatat data yang ada pada nilai tamadun SDIT Mafatih yaitu berupa form data siswa, nilai siswa dan laporan nilai tamadun siswa.

4. Studi Pustaka

Pada metode ini peneliti mempelajari materi yang berhubungan dengan karya tulis yang diajukan melalui beberapa buku, catatan kuliah dan sarana perpustakaan.

Tahapan yang peneliti lakukan adalah sebagai berikut :

1. Analisa kebutuhan perangkat lunak dengan mendapatkan data-data yang akan digunakan sebagai masukan dari sistem dan keluaran dari sistem.

2. Perancangan perangkat lunak yang diawali dengan perancangan database, antarmuka, lalu mengembangkan antarmuka sehingga bisa mempermudah pengguna dalam mengoperasikan sistem informasi ini. Setelahnya adalah melakukan validasi terhadap antarmuka.

3. Pembuatan kode program, sehingga fungsi-fungsi yang diharapkan bisa berjalan sesuai dengan yang dibutuhkan.

4. Pengujian perangkat lunak diantaranya dengan menemukan kesalahan dan juga memastikan semua fungsi berjalan sebagai mana yang dibutuhkan.

5. Penerapan atau implementasi perangkat lunak. Dalam tahapan ini biasanya dilakukan persiapan secara infrastuktur, komputer, melatih pengguna menggunakan sistem informasi ini, dan konversi dari sistem atau cara sebelumnya dengan sistem informasi yang dibutuhkan ini.

6. Pemeliharaan perangkat lunak. Tahapan terakhir dari siklus waterfall yaitu dengan melakukan perbaikan terhadap kesalahan yang terdapat pada perangkat lunak, penyesuaian infrastruktur dengan sistem yang baru, lalu menyempurnakan kemampuan peralatan atau infrastruktur, sehingga memberikan kinerja lebih baik.

7. Mengambil keputusan dalam menerapkan atau implementasi sistem informasi ini.

\section{HASIL DAN PEMBAHASAN}

Berdasarkan masalah-masalah yang dihadapi dalam sistem informasi nilai tamadun yang saat ini dilakukan pada SDIT Mafatih, maka peneliti memberikan alternative penyelesaian masalah sebagai berikut :

1. Membuat program berbasis Java dengan database MySQL sehingga sistem ini bisa terintegrasi

2. Perancangan sistem informasi nilai tamadun yang terkomputerisasi sehingga dapat menghasilkan informasi yang cepat, tepat dan akurat.

3. Pembuatan laporan secara otomatis sesuai dengan yang dibutuhkan. 
Berikut ini adalah Entity Relational Diagram yang diusulkan :

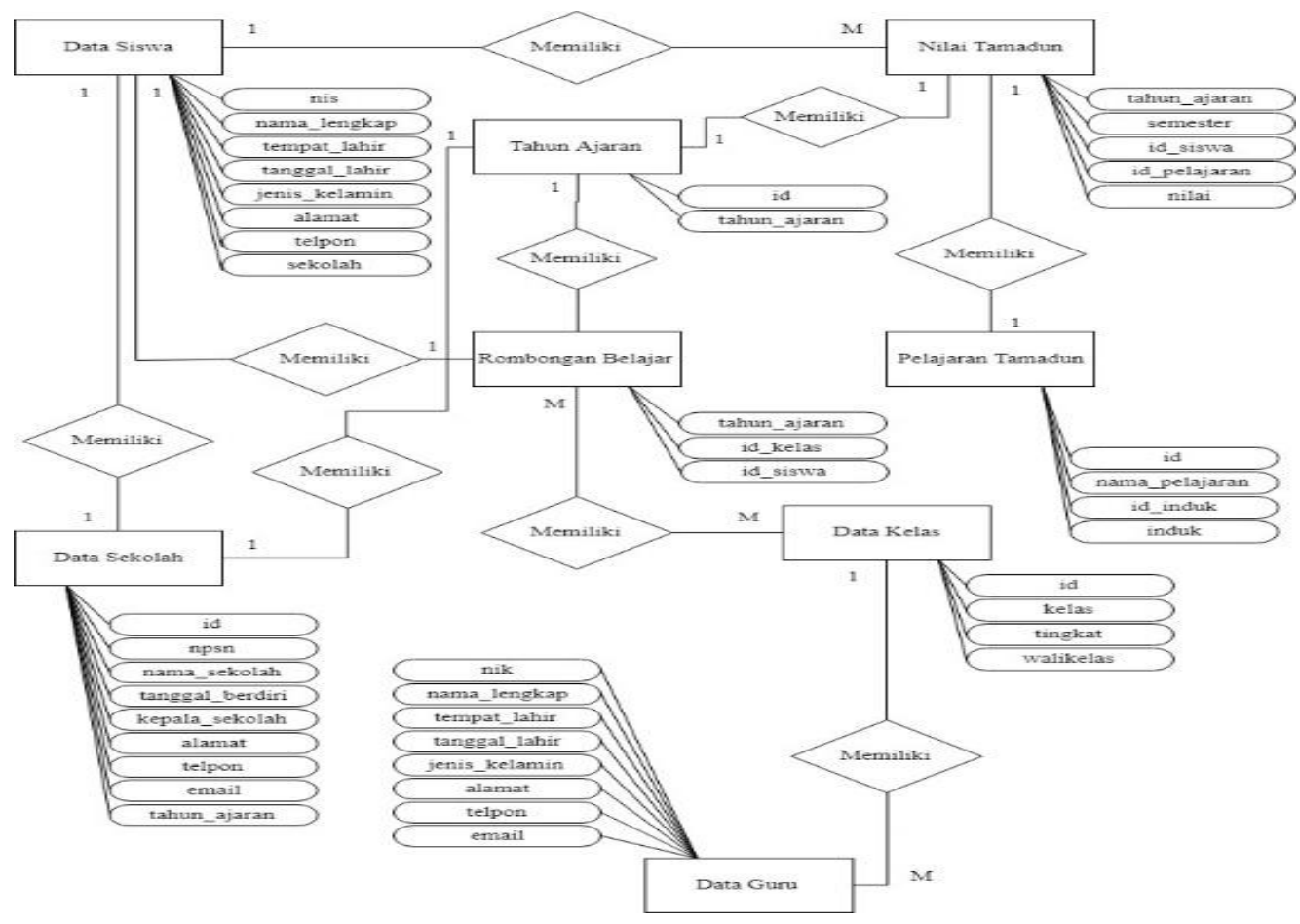

Gambar 1. ERD (Entity Relation Diagram)

\section{Tampilan layar}

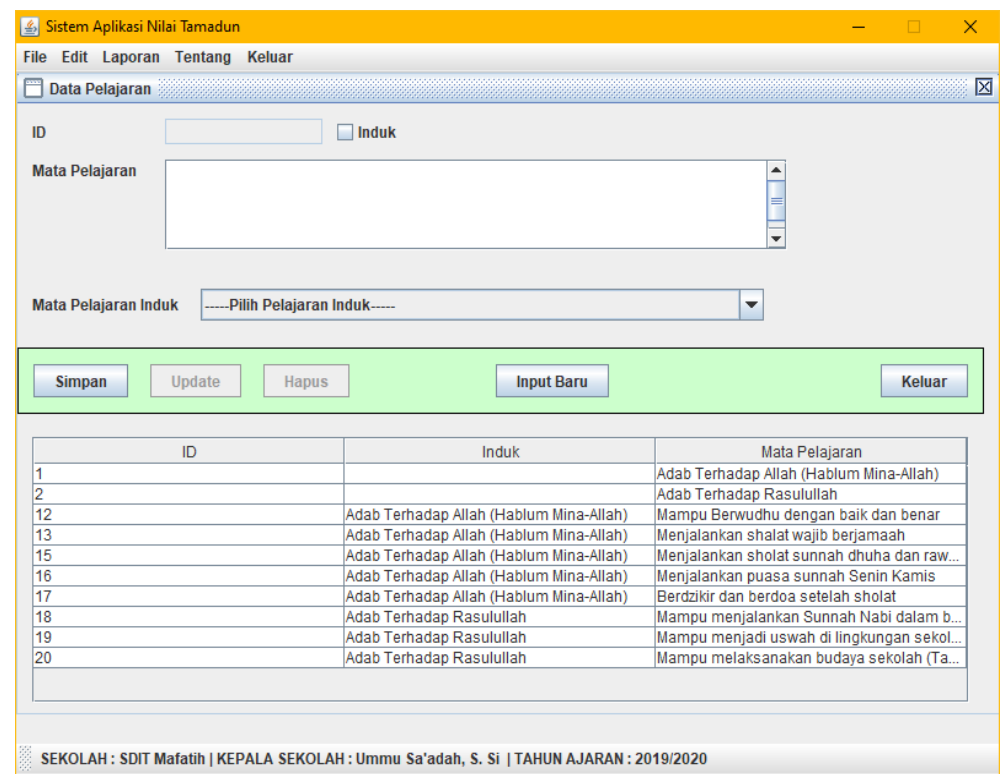

Gambar 2. Tampilan Menu Daftar Pelajaran Tamadun

Tampilan menu daftar pelajaran Tamadun ini berisi Daftar Pelajaran Tamadun dan cabangcabangnya. Karena dalam mata pelajaran tamadun, terdapat pelajaran inti, dan pelajaran cabang yang merupakan turunan dari pelajaran inti. 


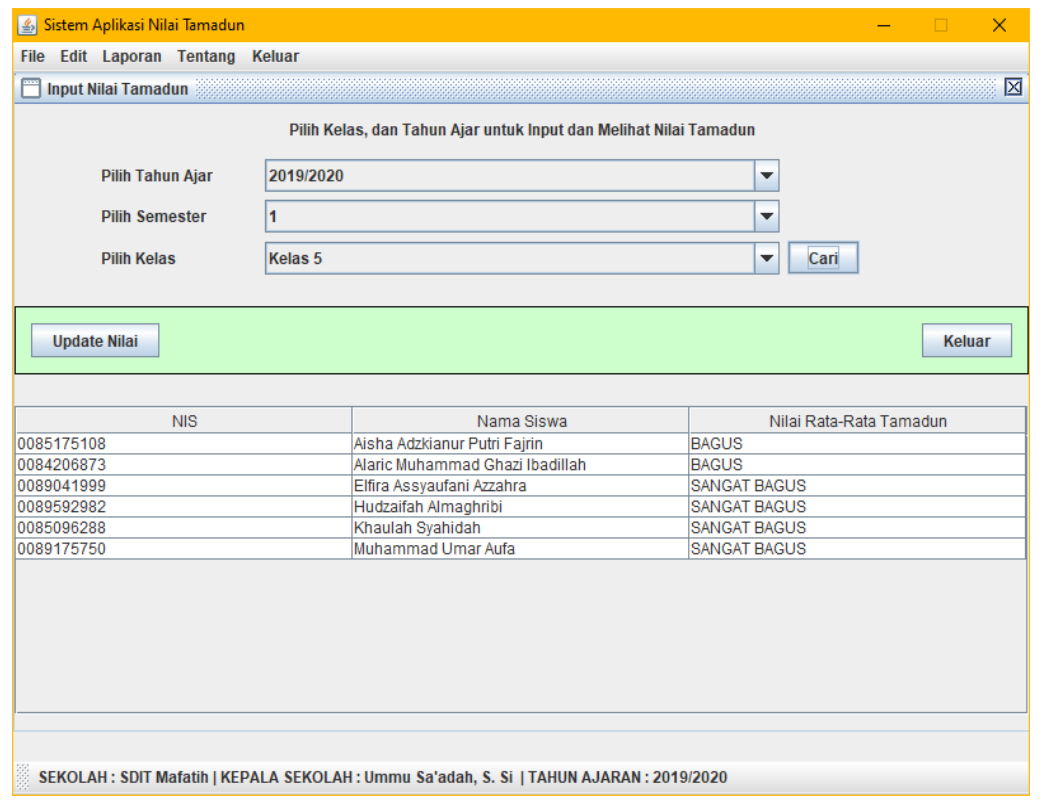

Gambar 3. Tampilan data Input Nilai Tamadun Per Kelas

Tampilan data input nilai ini adalah diisi setiap semester, dengan memilih tahun ajar, semester dan kelas, lalu akan muncul nilai rata-rata untuk siswa yang sudah diinput nilainya. Untuk memasukkan nilai tamadun, klik pada salah satu anak, lalu klik tombol update data, maka akan muncul tampilan dibawah ini.

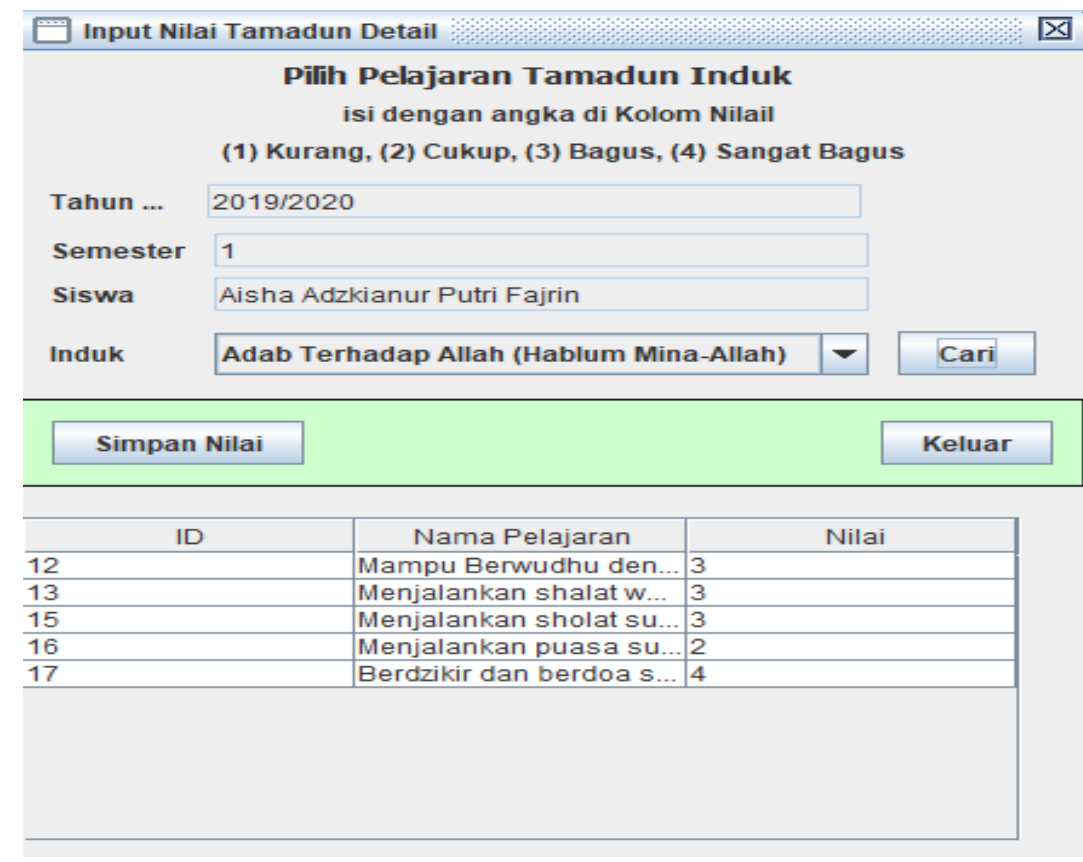

Gambar 4. Tampilan data input Nilai Per Siswa

Tampilan input nilai siswa akan muncul ketika klik tombol Update data dari tampilan sebelumnya. Untuk nilai dari setiap mata pelajaran tamadun cabang diisi dengan ukuran dari 1 (satu) yang berarti kurang, 2 (dua) berarti cukup, 3 (tiga) berarti bagus, dan 4 (empat) berarti sangat bagus. Untuk nilai mata pelajaran inti, akan merata-rata dari setiap pelajaran cabangnya. 


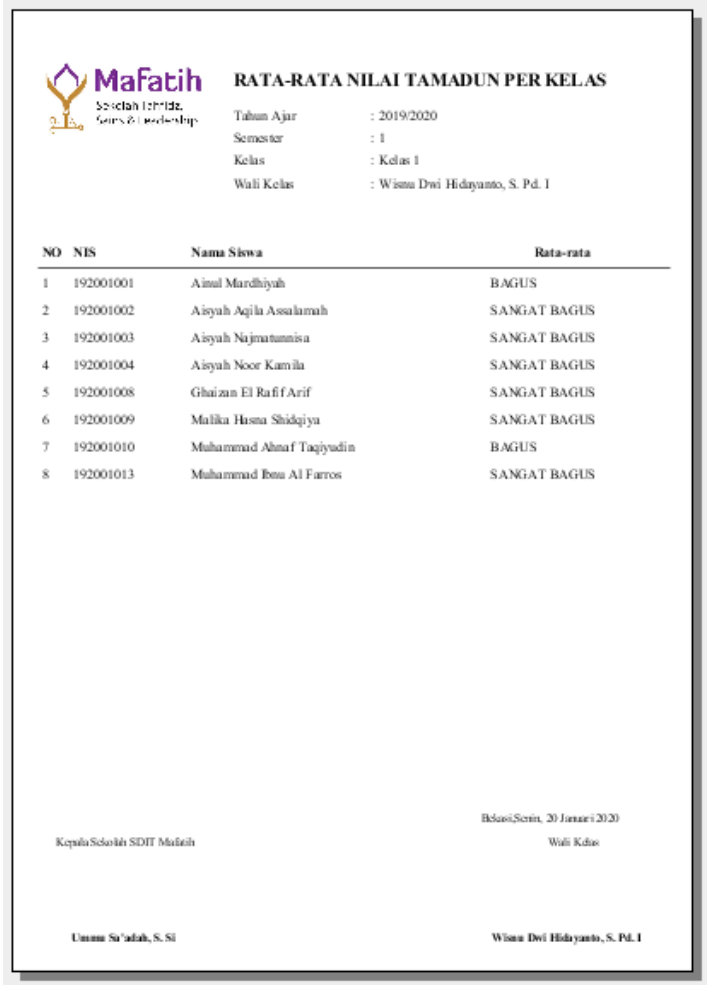

Gambar 5. Tampilan Laporan Nilai Tamadun Siswa Perkelas

Laporan nilai tamadun siswa per kelas ini akan dicetak oleh administrator, setiap selesai semester. Dan akan dilaporkan kepada kepala sekolah.

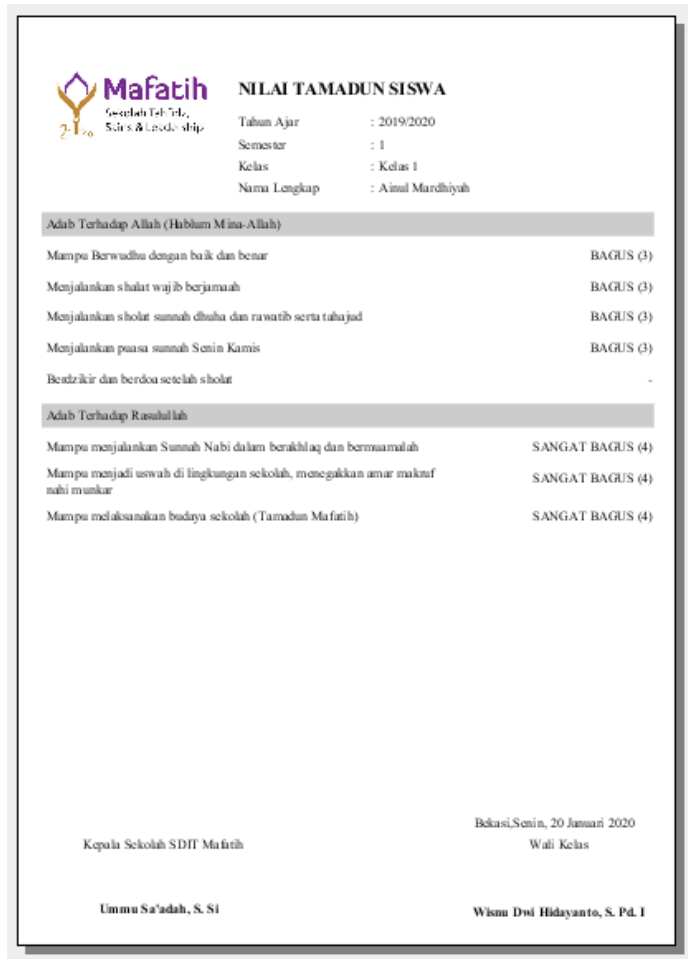

Gambar 6. Tampilan Laporan Nilai Tamadun Persiswa 
Laporan nilai tamadun per siswa akan dicetak oleh administrator, setiap selesai semester dan akan diserahkan kepada wali kelas, sehingga ketika pembagian raport, maka laporan nilai tamadun per siswa ini dilampirkan kepada wali murid.

\section{SIMPULAN}

Penelitian ini menjelaskan bagaimana sistem Informasi dapat memberikan kemudahan-kemudahan sebagai berikut :

1. Dengan sistem informasi Nilai Tamadun, data nilai tamadun bisa didapatkan dengan cepat, akurat dan efisien.

2. Dengan adanya sistem informasi nilai tamadun ini, nilai tamadun bisa didapatkan kapanpun, karena tersimpan di database yang akan mempermudah pengguna dalam menggunakannya.

3. Dengan adanya sistem informasi nilai tamadun ini, proses pencatatan dan pelaporan menjadi lebih tertata rapi dan bisa tepat waktu, juga sesuai dengan tugas dan wewenang masing-masing antara administrator, wali kelas, kepala sekolah.

4. Dengan adanya sistem informasi nilai tamadun ini, format laporan yang bisa disesuaikan dengan tahun ajar, semester dan kelas, menjadikan pengambilan keputusan lebih relevan dan mudah untuk diberikan.

5. Administrator dapat mengelola dan mengolah data nilai tamadun melalui sistem informasi nilai tamadun ini dengan lancar dan mudah.

\section{DAFTAR PUSTAKA}

Andrian, M. A. W. (2019). Perancangan Sistem Pengolahan Data Nilai Siswa berbasis Java di SMP At-Taqwa Kec. Sawah Besar Jakarta. STRING (Satuan Tulisan Riset Dan Inovasi Teknologi), 3(3), 267. https://doi.org/10.30998/string.v3i3.3584

Pratama, L. A., Primawati, A., \& Ariyani, L. (2019). Perancangan Sistem Informasi Sirkulasi Buku Pada Perpustakaan SMP Negeri 103 Jakarta. STRING (Satuan Tulisan Riset Dan Inovasi Teknologi), 4(2), 227. https://doi.org/10.30998/string.v4i2.4179

Purwanto, H., \& Raharja, A. A. (2019). Sistem Informasi ERP (Enterprise Resources Planning) untuk Mendukung Fungsi Bisnis pada PT. Cipta Mandiri Elektrindo. STRING (Satuan Tulisan Riset Dan Inovasi Teknologi), 4(1), 71. https://doi.org/10.30998/string.v4i1.3759

Rachmad, D. S. (2019). Perancangan Sistem Layanan Informasi Akademik Berbasis Web pada Fakultas Teknik Universitas Bhayangkara Jakarta Raya. STRING (Satuan Tulisan Riset Dan Inovasi Teknologi), 4(2), 140. https://doi.org/10.30998/string.v4i2.5347 